\title{
ARTICLE
}

Received 29 Jun 2015 | Accepted 8 Jul 2015 | Published 11 Aug 2015

DOI: $10.1038 /$ ncomms9034 OPEN

\section{Refining the pathway of carbide insertion into the nitrogenase M-cluster}

\author{
Jared A. Wiig', Yilin $\mathrm{Hu}^{1} \&$ Markus W. Ribbe ${ }^{1,2}$
}

Carbide insertion plays a pivotal role in the biosynthesis of $\mathrm{M}$-cluster, the cofactor of nitrogenase. Previously, we proposed a carbide insertion pathway involving methyltransfer from SAM to a FeS precursor and hydrogen abstraction from this methyl group that initiates the radical-based precursor maturation. Here we demonstrate that the methyl group is transferred to a precursor-associated sulfur before hydrogen abstraction, thereby refining the initial steps of the carbide insertion pathway.

\footnotetext{
${ }^{1}$ Department of Molecular Biology and Biochemistry, University of California, Irvine, California 92697-3900, USA. ${ }^{2}$ Department of Chemistry, University of California, Irvine, California 92697-2025, USA. Correspondence and requests for materials should be addressed to Y.H. (email: yilinh@uci.edu) or to M.W.R. (email: mribbe@uci.edu).
} 
M olybdenum (Mo) nitrogenase catalyses the reduction of nitrogen $\left(\mathrm{N}_{2}\right)$ to ammonia $\left(\mathrm{NH}_{3}\right)$ under ambient conditions at its active cofactor center ${ }^{1,2}$. Designated the M-cluster (Fig. 1), this complex metallocofactor has a $\left[\mathrm{MoFe}_{7} \mathrm{~S}_{9} \mathrm{C}\right]$ core that can be viewed as $\left[\mathrm{MoFe}_{3} \mathrm{~S}_{3}\right]$ and $\left[\mathrm{Fe}_{4} \mathrm{~S}_{3}\right]$ subclusters bridged by three $\mu_{2}$-sulfide atoms and one $\mu_{6}$-carbide ion $\left(\mathrm{C}^{4-}\right)$ in between, and it is further coordinated by an organic homocitrate moiety at its Mo end ${ }^{3-6}$. Since its discovery, the $\mu_{6}$-carbide at the centre of the M-cluster has attracted considerable attention because of its potential relevance to the structure and function of nitrogenase. More recently, a radical SAM-dependent pathway was identified for the incorporation of carbide into the M-cluster, generating new interest in elucidating the mechanistic details of this key event in the biosynthesis of M-cluster ${ }^{7,8}$.

Biosynthesis of the M-cluster involves the formation of a FeS core on a radical S-adenosyl-L-methionine (SAM) enzyme, NifB; and the subsequent maturation of this core into a mature $\mathrm{M}$-cluster on a scaffold protein, NifEN ${ }^{7-11}$. Previously, we demonstrated through studies of a NifEN-B fusion protein that, in the presence of SAM, NifB was capable of coupling a $\left[\mathrm{Fe}_{4} \mathrm{~S}_{4}\right]$ like cluster pair (designated the K-cluster, or the $\mathrm{FeS}$ precursor) into an $\left[\mathrm{Fe}_{8} \mathrm{~S}_{9} \mathrm{C}\right]$ cluster (designated the L-cluster, or the FeS core) concomitant with the incorporation of a carbide and a ' 9 th' sulfur ${ }^{7}$. Further, we identified the methyl group of SAM as the source of carbide and established hydrogen abstraction as the initial step to process this methyl group into a carbide ion $^{8}$. Together, these observations have led to the proposal of a carbide insertion pathway (Fig. 1), which involves: (i) the transfer of a methyl group from SAM to the K-cluster on NifB; (ii) the abstraction of a hydrogen atom from this methyl group by a $5^{\prime}$-deoxyadenosyl radical $\left(5^{\prime}\right.$-dA $\bullet$ ); and (iii) further deprotonation/dehydrogenation of the resultant methylene radical into a carbide ion concomitant with the insertion of the ' 9 th' sulfur and the radical-based rearrangement and coupling of the two $\left[\mathrm{Fe}_{4} \mathrm{~S}_{4}\right]$-like modules of the K-cluster into an $\left[\mathrm{Fe}_{8} \mathrm{~S}_{9} \mathrm{C}\right]$ $\mathrm{L}$-cluster ${ }^{7,8}$. The L-cluster is then matured into an M-cluster on NifEN following NifH-mediated insertion of Mo and homocitrate and transferred to its target binding site in NifDK, completing the assembly of M-cluster ${ }^{9,10}$. While attractive, certain details of this model, such as where the methyl group is initially attached on transfer and whether methyltransfer occurs before hydrogen abstraction, have remained unclear.

Here we show that the methyl group of SAM is transferred to a K-cluster-associated sulfur before hydrogen abstraction from this group takes place. This observation establishes the sequence of events during the initial phase of carbide insertion and reveals an interesting SN2-type reaction that involves direct methyltransfer to a metallosulfur cluster.

\section{Results}

Defining the initial point of methyl attachment. To pinpoint the entry point of the methyl group into the pathway of carbide insertion, NifEN-B was first incubated with SAM to allow methyltransfer to occur and subsequently treated by acid and analysed for methyl-bound species. Consistent with mobilization of the methyl group of SAM and abstraction of hydrogen from this methyl group by $5^{\prime}-\mathrm{dA} \bullet$, high-performance liquid chromatography (HPLC) analysis revealed that SAM was cleaved into $S$-adenosyl-L-homocysteine (SAH) and $5^{\prime}$-deoxyadenosine $\left(5^{\prime}-\mathrm{dAH}\right)$ on incubation with NifEN-B in the presence of a reductant, dithionite (Fig. 2a, trace 3). Substitution of [methyl- $d_{3}$ ] SAM for SAM in this incubation mixture resulted in the same HPLC profile as that of the cleavage of SAM, although $5^{\prime}$-dAD was generated in place of $5^{\prime}$-dAH as a result of hydrogen

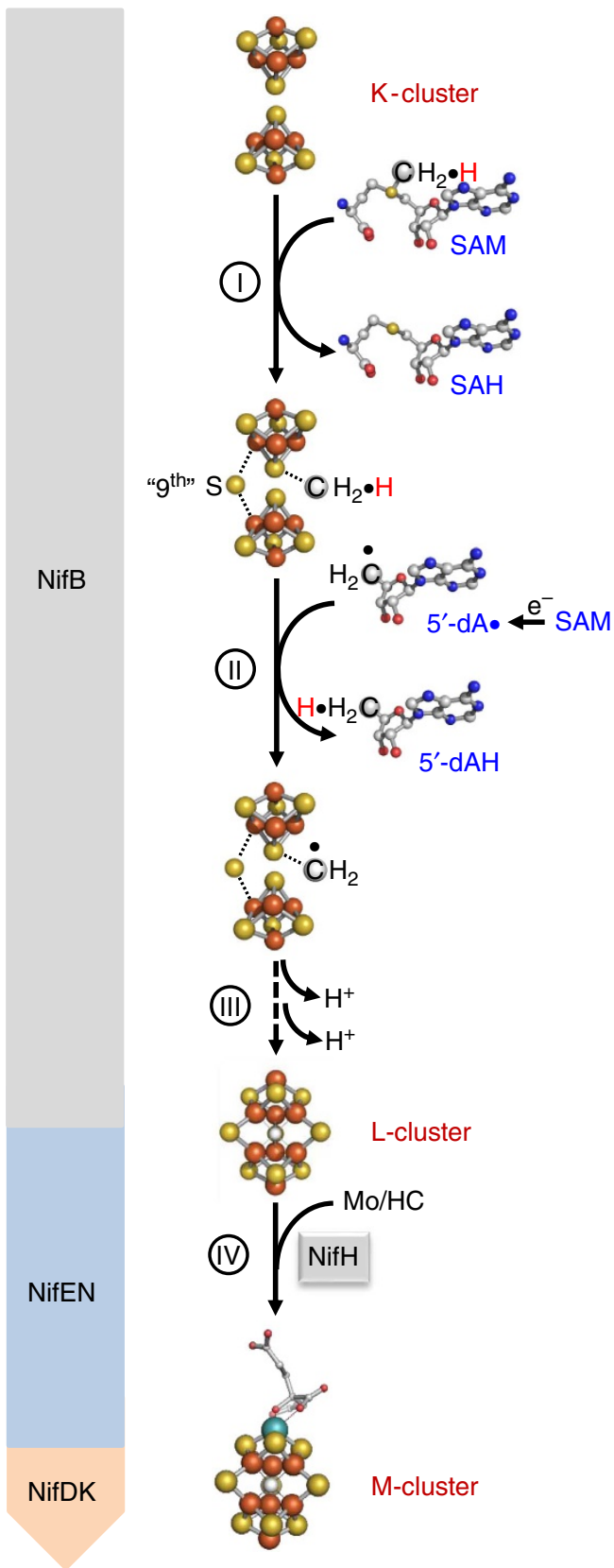

Figure 1 | Proposed carbide insertion pathway. It begins with the transfer of a methyl group from one equivalent of SAM to the K-cluster (I) and abstraction of a hydrogen atom from the methyl group by a 5-dA $\bullet$ radical that is generated upon homolytic cleavage of a second equivalent of SAM (II). The process continues with further dehydrogenation/deprotonation of the methylene radical concomitant with its incorporation into the L-cluster as an interstitial carbide atom (III). The L-cluster is further matured into an M-cluster on insertion of Mo and homocitrate (IV). The Nif proteins hosting events I-IV during the assembly of M-cluster are indicated in the figure. Atoms of the clusters are coloured as follows: Fe, orange; S, yellow; C, gray; Mo, cyan. HC, homocitrate.

abstraction from the deuterium-labelled methyl group (Fig. 2a, trace 4). Interestingly, when the incubation mixture comprising SAM, NifEN-B and dithionite were quenched by acid, a new, volatile product could be detected by gas chromatograph (GC) (Fig. 2b, black) and identified further by gas chromatographymass spectrometry (GC-MS) analysis as methanethiol $\left(\mathrm{CH}_{3} \mathrm{SH}\right)$ based on a mass-to-charge $(\mathrm{m} / \mathrm{z})$ ratio of 47 (Fig. 2b, inset). 
a
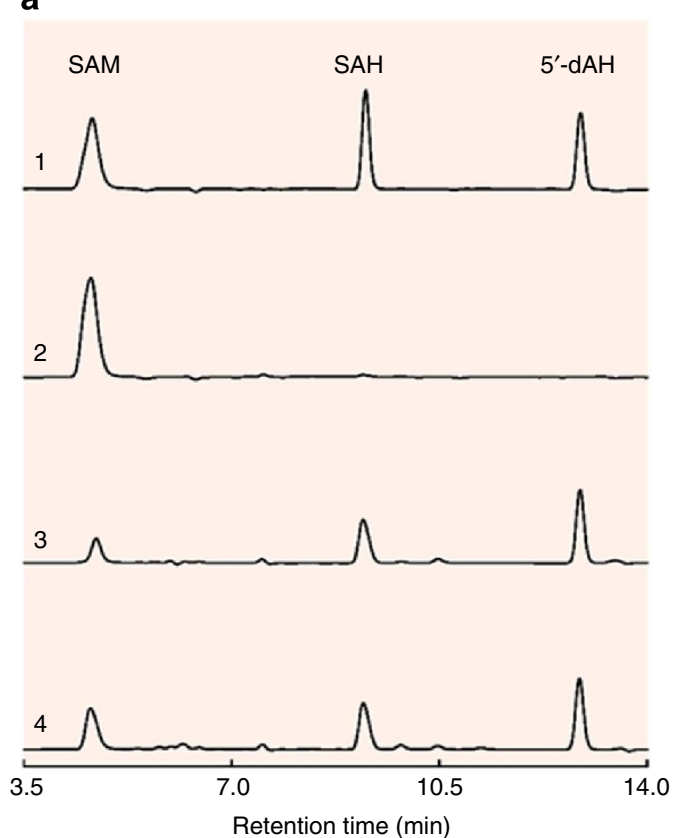

b

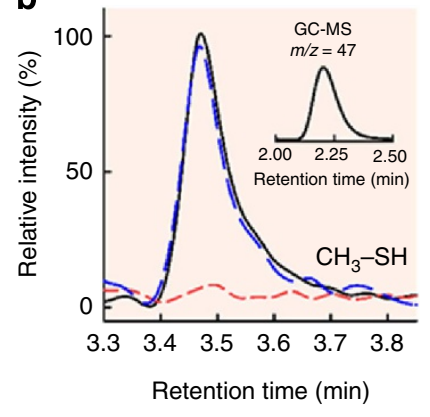

C

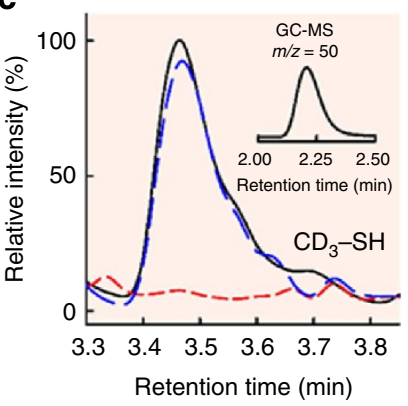

d
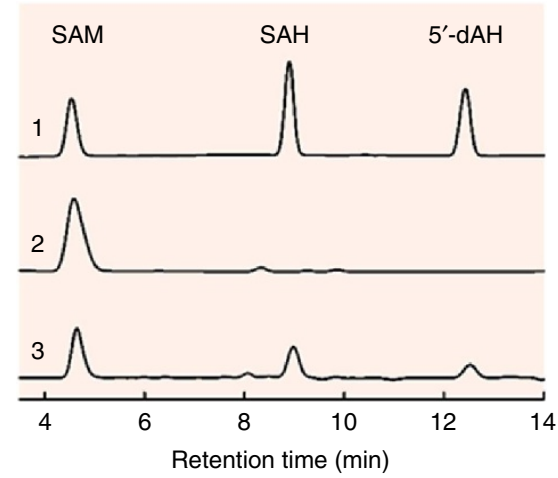

$\mathbf{f}$
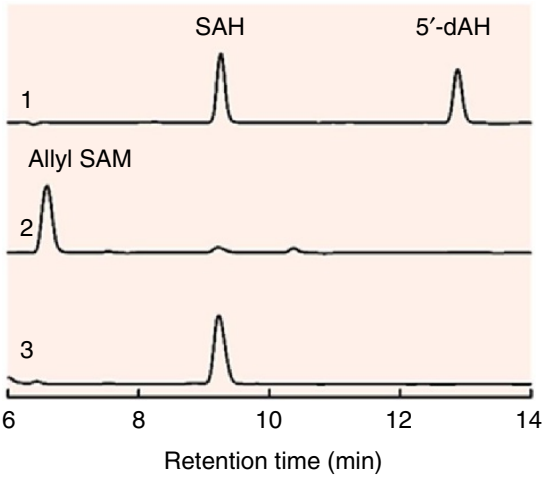

\section{e}

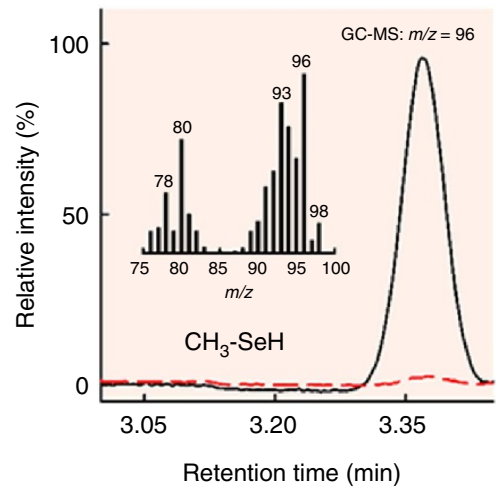

g

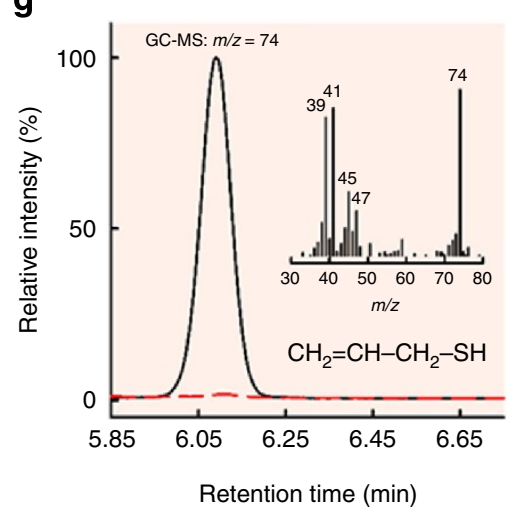

Figure 2 | HPLC analyses of cleavage products of SAM/analogs and GC/GC-MS analyses of acid-quenched products upon incubation of NifEN-B/ NifEN-B ${ }^{\text {FeSe }}$ with SAM/analogues. (a) HPLC elution profiles of (1) SAM, SAH and 5'-dAH standards; (2) SAM alone; (3) SAM and (4) [methyl- $d_{3}$ ] SAM in the presence of reduced NifEN-B. (b,c) GC-MS (inset) and GC analyses of acid-quenched incubation mixtures containing SAM (b) or [methyl- $d_{3}$ ] SAM (c), and NifEN-B in the reduced (black), oxidized (red) or re-reduced (blue) state. The acid-quenched products were identified as methanethiol (b, inset) and methane- $d_{3}$-thiol (c, inset) based on their GC retention times and respective $\mathrm{m} / z$ ratios of 47 and 50. (d) HPLC elution profiles of (1) SAM, SAH and $5^{\prime}$-dAH standards; (2) SAM alone; and (3) SAM in the presence of reduced NifEN-B ${ }^{\mathrm{FeSe}}$. (e) GC-MS full scan (inset) and SIM ( $\mathrm{m} / z=96$ ) analyses of acidquenched incubation mixtures containing reduced NifEN-BFeSe in the presence (black) and absence (red) of SAM. The acid-quenched product was identified as methylselenol based on its GC-MS retention time and fragmentation pattern. (f) HPLC elution profiles of (1) SAH and 5'-dAH standards; (2) allyl SAM alone; and (3) allyl SAM in the presence of reduced NifEN-B. (g) GC-MS full scan (inset) and SIM ( $\mathrm{m} / \mathrm{z}=74$ ) analyses of acid-quenched incubation mixtures containing reduced NifEN-B in the presence (black) and absence (red) of allyl SAM. The acid-quenched product was identified as allylthiol based on its GC-MS retention time and fragmentation pattern. 
Likewise, when the incubation mixture comprising [methyl- $d_{3}$ ] SAM, NifEN-B and reductant was quenched by acid, a volatile product with identical retention time to that of methanethiol could be detected on the same GC column (Fig. 2c, black). GC-MS analysis identified this product as methane- $d_{3}$-thiol $\left(\mathrm{CD}_{3} \mathrm{SH}\right)$ based on an $\mathrm{m} / z$ ratio of 50 (Fig. $2 \mathrm{c}$, inset), confirming that the methyl group in methanethiol originated from the methyl group of SAM.

The observation of attachment of this SAM-derived methyl group to an acid-labile sulfur atom is exciting, as it provides the first indication that the methyl group of SAM is transferred to a sulfur atom of a FeS cluster, such as one of the $\left[\mathrm{Fe}_{4} \mathrm{~S}_{4}\right]$ modules of the K-cluster in our proposed model (see Fig. 1). To further investigate the source of sulfur in the methanethiol product, NifEN-B was first treated with an iron chelator to remove its endogenous FeS clusters and then reconstituted with $\mathrm{FeCl}_{3} / \mathrm{Na}_{2} \mathrm{Se}$ or $\mathrm{FeCl}_{3} / \mathrm{Na}_{2} \mathrm{~S}$. When SAM was incubated with the $\mathrm{Fe} / \mathrm{Se}$ reconstituted NifEN-B protein (designated NifEN-B ${ }^{\mathrm{FeSe}}$ ) in the presence of dithionite, it was cleaved into $\mathrm{SAH}$ and $5^{\prime}-\mathrm{dAH}$ (Fig. 2d, trace 3)-the same products generated from SAM cleavage by the as-isolated NifEN-B or the Fe/S-reconstituted NifEN-B protein (designated NifEN-B ${ }^{\mathrm{FeS}}$ ) - although the efficiency of SAM cleavage by NifEN-B ${ }^{\mathrm{FeSe}}$ was lower than that by NifEN-B or NifEN-B FeS. When this incubation mixture was quenched by acid, a volatile product was detected by GC analysis and identified as methylselenol $\left(\mathrm{CH}_{3} \mathrm{SeH}\right)$ by $\mathrm{GC}-\mathrm{MS}$ analysis based on a $\mathrm{m} / \mathrm{z}$ ratio of 96 , as well as a characteristic fragmentation pattern of this compound (Fig. 2e, inset). This result firmly establishes the $S$ atom of a FeS cluster as the point of methyl group attachment and points to the possibility that this methyltransfer step occurs via an SN2-type reaction before the abstraction of a hydrogen atom from the methyl group.

'Uncoupling' methyltransfer and hydrogen abstraction. To investigate the sequence of events between methyltransfer and hydrogen abstraction, the two events were 'uncoupled' through substitution of allyl SAM, an analogue containing an allyl group $\left(-\mathrm{CH}_{2}-\mathrm{CH}=\mathrm{CH}_{2}\right)$ in place of a methyl group $\left(-\mathrm{CH}_{3}\right)$, for SAM in the incubation mixture containing NifEN-B and reductant. HPLC analysis demonstrated that allyl SAM was cleaved into $\mathrm{SAH}$ on incubation with NifEN-B and reductant, indicating that allyl transfer occurred during this process; however, no $5^{\prime}-\mathrm{dAH}$ could be detected in this case, suggesting that allyl SAM was incapable of undergoing homolytic cleavage to give rise to a $5^{\prime}$ $\mathrm{dA} \bullet$ radical for hydrogen abstraction from the allyl group (Fig. 2f, trace 3 ). When the incubation mixture comprising allyl SAM, NifEN-B and dithionite were quenched by acid and extracted into dichloromethane (DCM), a volatile product was detected by GC analysis (Fig. 2g, black) and identified as allylthiol $\left(\mathrm{CH}_{2}=\right.$ $\left.\mathrm{CH}-\mathrm{CH}_{2}-\mathrm{SH}\right)$ based on an $\mathrm{m} / z$ ratio of 74 and a characteristic fragmentation pattern of this compound (Fig. 2g, inset). This observation provides compelling evidence that the transfer of methyl group occurs before the abstraction of hydrogen by a $5^{\prime}-\mathrm{dA} \bullet$ radical while further implying that the initial methyltransfer from SAM to the $\mathrm{S}$ atom of $\mathrm{Fe}-\mathrm{S}$ cluster follows an SN2type mechanism.

Interestingly, while an SN2-type methyltransfer does not require the SAM-binding FeS cluster on NifEN-B to be present in a reduced state, the formation of methanethiol (Fig. 2b, red) or methane- $d_{3}$-thiol (Fig. $2 c$, red) was completely abolished when NifEN-B was oxidized by indigo disulfonate (IDS), but could be restored on re-reduction of the NifEN-B protein by dithionite (Fig. 2b,c, blue). Consistent with this observation, radiolabelling experiments demonstrated the transfer of methyl when NifEN-B was reduced by dithionite (Fig. 3, lanes 1, 2 and 5) and the

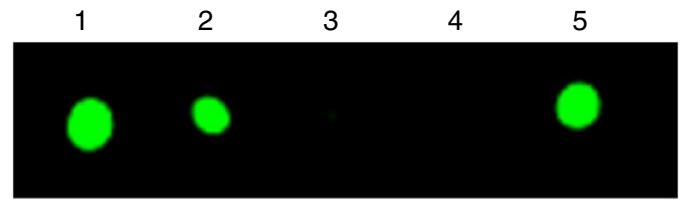

Figure 3 | Capture of NifEN-B proteins in different redox states on affinity (IMAC) resin after incubation with [methyl ${ }^{14}$ C] SAM. NifEN-B samples were as following: (1) reduced by excess dithionite; (2) reduced by dithionite, followed by removal of excess dithionite; (3) oxidized by IDS; (4) oxidized by IDS and then re-reduced by dithiothreitol; and (5) oxidized by IDS and then re-reduced by dithionite.

absence of this event when this protein was oxidized by IDS (Fig. 3, lane 3) or reduced by a weak reductant, dithiothreitol (DTT) (Fig. 3, lane 4). Together, these observations suggest that the K-cluster needs to be poised at a certain redox potential to render its associated sulfur atom more nucleophilic for the transfer of methyl group from SAM via an SN2-type nucleophilic substitution.

\section{Discussion}

While the post-hydrogen-abstraction events along the carbide insertion pathway are yet to be explored, the current work has established the first two steps in this process as an SN2-type methyltransfer from SAM to the sulfur atom of the K-cluster, followed by hydrogen abstraction of this SAM-derived methyl group by a $5^{\prime}$-dA $\bullet$ radical. Given that the endogenous FeS clusters could be removed from NifEN-B and readily reconstituted by $\mathrm{Fe} / \mathrm{S}$ or Fe/Se (see Fig. 2d,f) through a method specific for FeS cluster formation, the ' 9 th' sulfur that is required along with the carbide for the coupling and rearrangement of the two $\left[\mathrm{Fe}_{4} \mathrm{~S}_{4}\right]$ like cluster modules of $\mathrm{K}$-cluster into an $\left[\mathrm{Fe}_{8} \mathrm{~S}_{9}\right] \mathrm{L}$-cluster seems to be associated with the FeS cluster instead of the protein environment. One appealing scenario is that the ' 9 th' sulfur is a 'dangling' sulfur attached externally to one $\mathrm{Fe}$ atom of the K-cluster, which serves as the initial point of methyl attachment. Such 'dangling' sulfurs have been observed in the cases of other radical SAM-dependent enzymes such as RimO, MiaB and HydG $^{12,13}$, as well as the radical enzyme ( $R$ )-2-hydroxyisocaproyl-CoA dehydratase ${ }^{14}$, which enable a variety of important FeS chemistry in biological systems. Strategic labelling of this sulfur by Se may shed light on the insertion of this atom that is intertwined with the insertion of carbide, which could facilitate further refinement of the assembly pathway of M-cluster.

\section{Methods}

Unless noted otherwise, all chemicals and reagents were obtained from Fisher Scientific or Sigma-Aldrich. All proteins were handled under argon in an anaerobic chamber containing <4 p.p.m. $\mathrm{O}_{2}$.

Cell growth and protein purification. Azotobacter vinelandii was grown at $30^{\circ} \mathrm{C}$ in 180-1 batches in a 200-1 fermenter (New Brunswick Scientific) in Burke's minimal medium supplemented with $2 \mathrm{mM}$ ammonium acetate. Growth rates were monitored via cell density at $436 \mathrm{~nm}$ using a Spectronic 20 Genesys spectrometer (Spectronic Instruments). On ammonia depletion, cells were allowed to de-repress for $3 \mathrm{~h}$ before being harvested via a flow-through centrifugal harvester (Cepa). The cell paste was washed with $50 \mathrm{mM}$ Tris- $\mathrm{HCl}$ ( $\mathrm{pH}$ 8.0) buffer before it was frozen and stored at $-80^{\circ} \mathrm{C}$. Published methods were adapted to the purification of His-tagged NifEN-B ${ }^{7}$.

Radiolabel assays with [methyl- ${ }^{14} \mathbf{C}$ ] S-adenosyl-L-methionine. Five different reactions were assembled, each containing, in a total volume of $32 \mu \mathrm{l}, 100 \mathrm{mM}$ Tris- $\mathrm{HCl}$ (pH 8.0), $250 \mu \mathrm{M}$ [methyl- ${ }^{14} \mathrm{C}$ ] SAM (American Radiolabeled Chemicals, Inc.) and NifEN-B: (i) in the as-isolated state, where an excess $(10 \mathrm{mM}) \mathrm{Na}_{2} \mathrm{~S}_{2} \mathrm{O}_{4}$ was supplied; (ii) in a reduced state, where excess $\mathrm{Na}_{2} \mathrm{~S}_{2} \mathrm{O}_{4}$ was removed from the as-isolated NifEN-B (see i) via gel filtration with Sephadex G-25 fine resin 
(GE Healthcare); (iii) in an oxidized state, where $\mathrm{Na}_{2} \mathrm{~S}_{2} \mathrm{O}_{4}$-free NifEN-B was oxidized with excess IDS, followed by the removal of excess IDS via AG1-X8 resin (Bio-Rad); (iv) in a weakly reduced state, in which oxidized NifEN-B was re-reduced by the addition of $5 \mathrm{mM}$ DTT; and (v) in a re-reduced state, where the $\mathrm{Na}_{2} \mathrm{~S}_{2} \mathrm{O}_{4}$-free NifEN-B (see ii) was first oxidized by IDS and then re-reduced by the addition of $10 \mathrm{mM} \mathrm{Na}_{2} \mathrm{~S}_{2} \mathrm{O}_{4}$. All reactions were incubated for $30 \mathrm{~min}$ at $25^{\circ} \mathrm{C}$ with intermittent mixing before being passed over Immobilized-metal affinity chromatography (IMAC) sepharose resin (10 $\mu$ l packed volume; GE Healthcare) that was equilibrated with a buffer containing $25 \mathrm{mM}$ Tris- $\mathrm{HCl}$ ( $\mathrm{pH}$ 8.0), $10 \%$ glycerol and $500 \mathrm{mM} \mathrm{NaCl}$. The IMAC sepharose resin was washed three times with $700 \mu \mathrm{l}$ buffer containing $25 \mathrm{mM}$ Tris- $\mathrm{HCl}$ (pH 8.0), $10 \%$ glycerol, $500 \mathrm{mM} \mathrm{NaCl}$ and $40 \mathrm{mM}$ imidazole. The IMAC sepharose samples were then re-suspended in the wash buffer and applied directly onto a piece of Whatman 3-MM chromatography paper. The blots were dried and exposed to a GE Healthcare Storage Phosphor Screen GP $(20 \times 25 \mathrm{~cm})$ for $48 \mathrm{~h}$ before imaging on a GE Healthcare Typhoon Trio $^{+}$variable mode imager.

Selenium labelling experiment of NifEN-B. To generate selenium (Se)-labelled clusters on NifEN-B, the protein was first treated by an iron chelator that removed the endogenous iron-sulfur (FeS) cluster species from the protein, followed by re-isolation of the apo NifEN-B from the mixture. Specifically, $18 \mu \mathrm{M}$ NifEN-B was incubated with $20 \mathrm{mM}$ bathophenanthroline disulfonate in the presence of $2 \mathrm{mM}$ $\mathrm{Na}_{2} \mathrm{~S}_{2} \mathrm{O}_{4}, 25 \mathrm{mM}$ Tris- $\mathrm{HCl}$ ( $\mathrm{pH} 8.0$ ) and $10 \%$ glycerol for 30 min with gentle stirring. Subsequently, bathophenanthroline disulfonate was removed from the protein by passing the incubation mixture via a $10 \mathrm{ml}$ packed Q-Sepharose Fast Flow column (GE Healthcare). The resultant apo NifEN-B was nearly colourless, exhibited no signal in electron paramagnetic resonance spectroscopy, and displayed no capability to serve as a precursor source in the L-cluster maturation assay ${ }^{7}$, suggesting that its endogenous $\mathrm{FeS}$ clusters have been removed.

The apo NifEN-B protein was chemically reconstituted with $\left[\mathrm{Fe}_{4} \mathrm{~S}_{4}\right]$ or $\left[\mathrm{Fe}_{4} \mathrm{Se}_{4}\right]$ clusters following a procedure adapted from a previously published method ${ }^{15}$. First, $\mathrm{Na}_{2} \mathrm{~S}_{2} \mathrm{O}_{4}$ was removed from NifEN-B via gel filtration with Sephadex G-25 fine resin. Then, $10 \mathrm{mM}$ DTT was supplement to a solution containing $17 \mu \mathrm{M}$ NifEN-B, $25 \mathrm{mM}$ Tris- $\mathrm{HCl}$ (pH 8.0), $5 \%$ glycerol and $250 \mathrm{mM} \mathrm{NaCl}$, and incubated on ice with gentle stirring for $10 \mathrm{~min}$. $\mathrm{Next}, \mathrm{FeCl}_{3}$ was slowly added to achieve a final concentration of $1 \mathrm{mM}$ and the reaction was allowed to incubate for $5 \mathrm{~min}$. Subsequently, $\mathrm{Na}_{2} \mathrm{~S}$ or $\mathrm{Na}_{2} \mathrm{Se}$ was added to the reaction over a time period of $10 \mathrm{~min}$ to achieve a final concentration of $1 \mathrm{mM}$. The reaction was incubated in an ice water bath with gentle stirring for $1 \mathrm{~h}$ before being passed through the IMAC sepharose resin. The reconstituted NifEN-B protein that was bound to the IMAC sepharose resin was washed three times with four column volumes of a buffer containing $25 \mathrm{mM}$ Tris- $\mathrm{HCl}$ ( $\mathrm{pH} 8.0$ ), $2 \mathrm{mM} \mathrm{Na}_{2} \mathrm{~S}_{2} \mathrm{O}_{4}, 10 \%$ glycerol, $500 \mathrm{mM} \mathrm{NaCl}$ and $40 \mathrm{mM}$ imidazole and subsequently eluted in a buffer containing $25 \mathrm{mM}$ Tris- $\mathrm{HCl}$ ( $\mathrm{pH} \mathrm{8.0),} 2 \mathrm{mM} \mathrm{Na}_{2} \mathrm{~S}_{2} \mathrm{O}_{4}, 10 \%$ glycerol, $500 \mathrm{mM} \mathrm{NaCl}$ and $250 \mathrm{mM}$ imidazole. The successful reconstitution of apo NifEN-B with $\left[\mathrm{Fe}_{4} \mathrm{~S}_{4}\right]$ clusters (designated NifEN-B ${ }^{\mathrm{FeS}}$ ) or $\left[\mathrm{Fe}_{4} \mathrm{Se}_{4}\right]$ clusters (designated NifEN-B ${ }^{\mathrm{FeSe}}$ ) was confirmed by electron paramagnetic resonance analysis and cluster maturation assay $^{7}$. NifEN-B ${ }^{\mathrm{FeSe}}$ was $40 \%$ active relative to NifEN-B in the cluster maturation assays.

Generation of allyl SAM. Allyl SAM, which contains an allyl group $\left(\mathrm{CH}_{2}=\right.$ $\left.\mathrm{CH}-\mathrm{CH}_{2}-\right)$ in place of a methyl group $\left(\mathrm{CH}_{3}-\right)$, was generated via an alkylation reaction following a procedure adapted from previously published methods ${ }^{16,17}$, in which $25 \mathrm{mg} \mathrm{SAH}$ was dissolved in $200 \mu \mathrm{l}$ of a chilled acid solution consisting of formic acid and acetic acid at 1:1 ratio. Next, $80 \mu \mathrm{l}$ of 3-bromo-1-propene was added and the reaction was incubated with stirring for $96 \mathrm{~h}$ before addition of $2 \mathrm{ml}$ $\mathrm{H}_{2} \mathrm{O}$ to quench the reaction. The aqueous phase was extracted three times with $2 \mathrm{ml}$ diethyl ether. Then, the lower, aqueous phase was lyophilized to dryness and dissolved in $300 \mu \mathrm{l} \mathrm{H}_{2} \mathrm{O}$ with $0.02 \%$ Trifluoroacetic acid (TFA) before allyl SAM was purified by HPLC using an Agilent 1200 Series HPLC system (Santa Clara, CA) equipped with a Supelcosil LC-18-T column $(15 \mathrm{~cm} \times 4.6 \mathrm{~mm}, 5-\mu \mathrm{M}$ particle size). The column was equilibrated with $98 \%$ buffer A $\left(50 \mathrm{mM} \mathrm{KH}_{2} \mathrm{PO}_{4}, \mathrm{pH} 6.6\right)$ and $2 \%$ buffer $\mathrm{B}(100 \%$ methanol). Following each $20-\mu \mathrm{l}$ injection, the column was subjected to a linear gradient of $2-15 \%$ buffer B over $10 \mathrm{~min}$, a linear gradient of $15-80 \%$ buffer B over $1 \mathrm{~min}$, and an isocratic flow of $80 \%$ buffer B for $3 \mathrm{~min}$. The flow rate of buffer was $1 \mathrm{ml} \mathrm{min}^{-1}$ throughout each run and the column was maintained at $25^{\circ} \mathrm{C}$. The column was prepared for subsequent sample injections by applying a gradient of $80-2 \%$ buffer B over $1 \mathrm{~min}$, followed by an isocratic flow of $2 \%$ buffer B for $2 \mathrm{~min}$. Under these conditions, allyl SAM was eluted between 3.4 and $4.2 \mathrm{~min}$ based on ultraviolet monitoring at $254 \mathrm{~nm}$ and confirmed to have a mass-to-charge $(\mathrm{m} / \mathrm{z})$ ratio of 425 via electrospray ionization mass spectrometry analysis.

SAM cleavage assays. The SAM cleavage assays contained, in a total volume of $0.5 \mathrm{ml}, 25 \mathrm{mM}$ Tris-HCL (pH 8.0), $5 \%$ glycerol, $16 \mu \mathrm{M} \mathrm{Na} \mathrm{S}_{2} \mathrm{O}_{4}$-free NifEN-B, NifEN-B ${ }^{\mathrm{FeS}}$ or NifEN-B $\mathrm{FeSe}$ and $10 \mu \mathrm{M}$ SAM, [methyl- $d_{3}$ ] SAM or allyl SAM. Assays were incubated at $25^{\circ} \mathrm{C}$ for $30 \mathrm{~min}$ with intermittent mixing, before being terminated by filtration with Amicon Ultra 30,000 MWCO centrifugal filters. TFA was supplemented at a concentration of $0.14 \%$ to the filtered samples before the samples were analysed using a Thermo Scientific Dionex Ultimate 3000 UHPLC system with an Acclaim $120 \mathrm{C} 18$ column $(4.6 \times 100 \mathrm{~mm}, 5-\mu \mathrm{m}$ particle size). The column was equilibrated with $98 \%$ buffer A $\left(50 \mathrm{mM} \mathrm{KH}_{2} \mathrm{PO}_{4}, \mathrm{pH} 6.6\right)$ and $2 \%$ buffer B (100\% methanol). Following each $100-\mu$ injection of sample, a linear gradient of $2-60 \%$ buffer B was applied over $20 \mathrm{~min}$, followed by $10 \mathrm{~min}$ of isocratic flow with $60 \%$ buffer B and a linear gradient of $60-2 \%$ buffer B over $5 \mathrm{~min}$. The buffer flow rate was $0.5 \mathrm{ml} \mathrm{min}^{-1}$ throughout each run and the column was maintained at $30^{\circ} \mathrm{C}$. The column was then equilibrated for 5 min with $2 \%$ buffer B before subsequent sample injections. The elution of SAM or allyl SAM cleavage products were monitored by ultraviolet at $254 \mathrm{~nm}$.

Acid-quenching experiments. A published method was adapted for the NifEN-Bdependent production of methanethiol, methylselenol or allylthiol ${ }^{12}$. First, excess $\mathrm{Na}_{2} \mathrm{~S}_{2} \mathrm{O}_{4}$ was removed from NifEN-B via gel filtration with Sephadex G-25 fine resin that was equilibrated with an oxygen-free buffer containing $25 \mathrm{mM}$ Tris- $\mathrm{HCl}$ ( $\mathrm{pH}$ 8.0). Immediately following the removal of excess reductant, $4 \mathrm{nmol}$ of NifEN$\mathrm{B}$ or NifEN-B $\mathrm{B}^{\mathrm{FeSe}}$ was added to a sealed $300-\mu$ l glass vial, which contained $200 \mathrm{nmol}$ SAM, [methyl- $d_{3}$ ] SAM or allyl SAM in a total volume of $100 \mu$ l, as well as $100 \%$ argon at $2 \mathrm{psi}$ in the headspace. The $100 \mu \mathrm{l}$ reactions were then incubated for $30 \mathrm{~min}$ at $25^{\circ} \mathrm{C}$ before being quenched by $25 \mu \mathrm{l}$ of $1 \mathrm{M} \mathrm{HCl}$.

To observe the formation of the volatile methanethiol, methane- $d_{3}$-thiol, or methylselenol, the acid-quenched samples were incubated at $60^{\circ} \mathrm{C}$ for $15 \mathrm{~min}$ and equilibrated to room temperature for $10 \mathrm{~min}$ before the entire headspace was injected by a gas-tight syringe onto a GC with flame photometric detection (SRI Instruments 8610C with a Restek Rt-XLSulfur column; $1 \mathrm{~m}, 0.75 \mathrm{~mm}$ ID) or a GC-MS (ThermoFisher Scientific Trace 1300 GC connected to a Thermo-Fisher Scientific ISQ QD single quadrupole mass spectrometry) with a Restek Rxi-1ms column ( $30 \mathrm{~m}, 0.32 \mathrm{~mm}$ ID, $4.0 \mu \mathrm{m} \mathrm{df}$ ). The GC inlet and oven temperatures were maintained at $30^{\circ} \mathrm{C}$ (for methanethiol or methane- $d_{3}$-thiol analysis) or $50^{\circ} \mathrm{C}$ (for methylselenol analysis), while the mass spectrometry transfer line and ion source were maintained at $250{ }^{\circ} \mathrm{C}$ Total ion chromatograms were generated under SIM conditions in electron ionization mode, with $\mathrm{m} / z=47$ for methanethiol detection, $\mathrm{m} / \mathrm{z}=50$ for methane$d_{3}$-thiol detection, and $m / z=96$ for methylselenol detection. These base peaks were selected based on characterization of standard samples (Sigma-Aldrich) under full scan conditions and comparison to those reported in the National Institute of Standards and Technology database. Approximately $50 \%$ of the maximum possible yield of methanethiol or methane- $d_{3}$-thiol was detected in these experiments.

To observe the formation of allylthiol, the acid-quenched samples were incubated at $25^{\circ} \mathrm{C}$ for $10 \mathrm{~min}$ before allylthiol was extracted into $100 \mu \mathrm{l}$ of dichloromethane under anaerobic conditions. The DCM-extracted allylthiol was incubated at $60^{\circ} \mathrm{C}$ for $15 \mathrm{~min}$ in sealed 300- $\mu$ l glass vials and equilibrated to room temperature for $10 \mathrm{~min}$ before the entire headspace was injected onto a GC-MS (Thermo-Fisher Scientific Trace 1300 GC connected to a Thermo-Fisher Scientific ISQ QD single quadrupole mass spectrometry) with a Restek Rxi 1-ms column $(30 \mathrm{~m}, 0.32 \mathrm{~mm}$ ID, $4.0 \mu \mathrm{m} \mathrm{df})$ The inlet and oven temperatures of the GC were kept at $30^{\circ} \mathrm{C}$, while the mass spectrometry transfer line and ion source were maintained at $250^{\circ} \mathrm{C}$. Total ion chromatograms were generated for samples under SIM conditions $(m / z=74)$ or full scan conditions $(m / z=30-80)$ in electron ionization mode. The base peak was selected based on characterization of an allylthiol standard (Sigma-Aldrich) under full scan conditions and comparison with those reported in the National Institute of Standards and Technology database. Approximately $30 \%$ of the maximum possible yield of allylthiol was detected in these experiments.

\section{References}

1. Burgess, B. K. \& Lowe, D. J. Mechanism of molybdenum nitrogenase. Chem. Rev. 96, 2983-3012 (1996).

2. Rees, D. C. et al. Structural basis of biological nitrogen fixation. Philos. Trans. A Math. Phys. Eng. Sci. 363, 971-984 (2005).

3. Chan, M. K., Kim, J. \& Rees, D. C. The nitrogenase FeMo-cofactor and P-cluster pair: $2.2 \AA$ resolution structures. Science 260, 792-794 (1993).

4. Einsle, O. et al. Nitrogenase MoFe-protein at $1.16 \AA$ resolution: a central ligand in the FeMo-cofactor. Science 297, 1696-1700 (2002).

5. Spatzal, T., Perez, K. A., Einsle, O., Howard, J. B. \& Rees, D. C. Evidence for interstitial carbon in nitrogenase FeMo cofactor. Science 334, 940 (2011).

6. Lancaster, K. M. et al. X-ray emission spectroscopy evidences a central carbon in the nitrogenase iron-molybdenum cofactor. Science 334, 974-977 (2011).

7. Wiig, J. A., Hu, Y. \& Ribbe, M. W. NifEN-B complex of Azotobacter vinelandii is fully functional in nitrogenase FeMo cofactor assembly. Proc. Natl Acad. Sci. USA 108, 8623-8627 (2011).

8. Wiig, J. A., Hu, Y., Lee, C. C. \& Ribbe, M. W. Radical SAM-dependent carbon insertion into the nitrogenase M-cluster. Science 337, 1672-1675 (2012).

9. Hu, Y. et al. FeMo cofactor maturation on NifEN. Proc. Natl Acad. Sci. USA 103, 17119-17124 (2006)

10. Hu, Y. et al. Nitrogenase Fe protein: A molybdate/homocitrate insertase. Proc Natl Acad. Sci. USA 103, 17125-17130 (2006).

11. Ribbe, M. W., Hu, Y., Hodgson, K. O. \& Hedman, B. Biosynthesis of nitrogenase metalloclusters. Chem. Rev. 114, 4063-4080 (2014).

12. Landgraf, B. J., Arcinas, A. J., Lee, K. H. \& Booker, S. J. Identification of an intermediate methyl carrier in the radical $S$-adenosylmethionine 
methylthiotransferases RimO and MiaB. J. Am. Chem. Soc. 135, 15404-15416 (2013).

13. Dinis, P. et al. X-ray crystallographic and EPR spectroscopic analysis of HydG, a maturase in [FeFe]-hydrogenase H-cluster assembly. Proc. Natl Acad. Sci. U.S.A. 112, 1362-1367 (2015).

14. Knauer, S. H., Buckel, W. \& Dobbek, H. Structural basis for reductive radical formation and electron recycling in (R)-2-hydroxyisocaproyl-CoA dehydratase. I. Am. Chem. Soc. 133, 4342-4347 (2011).

15. Moulis, J. M. \& Meyer, J. Characterization of the selenium-substituted 2 [4Fe-4Se] ferredoxin from Clostridium pasteurianum. Biochemistry 21, 4762-4771 (1982).

16. Dalhoff, C., Lukinavicius, G., Klimasauskas, S. \& Weinhold, E. Direct transfer of extended groups from synthetic cofactors by DNA methyltransferases. Nat. Chem. Bio. 2, 31-32 (2006).

17. Dalhoff, C., Lukinavicius, G., Klimasauskas, S. \& Weinhold, E. Synthesis of $S$-adenosyl-L-methionine analogues and their use for sequence-specific transalkylation of DNA by methyltransferases. Nat. Protoc. 1, 1879-1886 (2006).

\section{Acknowledgements}

This work was supported by NIH grant GM 67626 (M.W.R.).

\section{Author contributions}

J.A.W. performed the experiments, J.A.W., Y.H. and M.W.R. designed the research and analysed the data, Y.H. and M.W.R. supervised the research and wrote the manuscript.

\section{Additional information}

Competing financial interests: The authors declare no competing financial interests.

Reprints and permission information is available online at http://npg.nature.com/ reprintsandpermissions/

How to cite this article: Wiig, J. A. et al. Refining the pathway of carbide insertion into the nitrogenase M-cluster. Nat. Commun. 6:8034 doi: 10.1038/ncomms9034 (2015).

(c) (i) This work is licensed under a Creative Commons Attribution 4.0 International License. The images or other third party material in this article are included in the article's Creative Commons license, unless indicated otherwise in the credit line; if the material is not included under the Creative Commons license, users will need to obtain permission from the license holder to reproduce the material. To view a copy of this license, visit http://creativecommons.org/licenses/by/4.0/ 